UTILITY: Jurnal IImiah Pendidikan dan Ekonomi

Volume 5, No. 2, Agustus 2021: Page 11-20

ISSN 2549-1377 (Print) || ISSN 2549-1385 (Online)

Available online at $h$ ttp://journal.stkipnurulhuda.ac.id/index.php/utility

\title{
PENGARUH DISIPLIN KERJA TERHADAP KINERJA GURU DI SMK NEGERI 3 PALEMBANG
}

\author{
Abdurrahman ${ }^{1}$ \\ ${ }^{1}$ Politeknik Darussalam \\ *E-mail: a.rachman1407@gmail.com
}

\begin{abstract}
Abstrak: Profesionalisme seorang guru dapat dilihat dari kedisiplinannya, tanggung jawab dalam mendidik merupakan tolak ukur kinerjanya. Guru yang profesional adalah guru yang menerapkan prinsip kedisiplinan. Penelitian merupakan penelitian kuantitaif yang bertujuan untuk mengetahui seberapa besar pengaruh Disiplin Kerja (X1) terhadap variabel dependent Kinerja Guru di SMK Negeri 3 Palembang. Teknik yang digunakan dalam pengambilan sampel adalah purposive sampling. Jumlah sampel yang digunakan dalam penelitian sebanyak 56 responden. Instrumen pengukuran variabel adalah validitas dan reliabilitas sedangkan teknik analisis yang digunakan uji T dan analisis regresi sederhana. Dari hasil uji T (parsial), Disiplin Kerja (X1) berpengaruh terhadap Kinerja Gurudi SMK Negeri 3 Palembang dengan taraf signifikansi kurang dari $5 \%$ dengan nilai $t_{\text {hitung }}$ untuk variabel Disiplin Kerja adalah sebesar 5,309 dan $t_{\text {tabel }}$ dengan $\alpha=5 \%$ dengan demikian $t_{\text {hitung }}$ lebih besar dari $t_{\text {tabel }}$ $(5,309>1,674)$, artinya Disiplin Kerja berpengaruh secara Positif.
\end{abstract}

\section{Kata Kunci: Disiplin Kerja dan Kinerja Guru}

\section{PENDAHULUAN}

Dunia pendidikan merupakan institusi yang mempunyai peranan penting dalam meningkatkan kualitas sumber daya manusia. Peran ini terkait dengan upaya menjadikan generasi penerus bangsa yang mempunyai kualitas sumber daya manusia yang dapat diandalkan. Salah satu faktor penunjang pendidikan adalah manusia dalam hal ini adalah sumber daya manusia, lembaga pendidikan akan berhasil jika memiliki Sumber Daya Manusia yang berkualitas dan profesional (Wahyuni, 2015).

Profesionalisme guru adalah kemampuan guru untuk melakukan tugas pokoknya sebagai pendidik dan pengajar meliputi kemampuan merencanakan, melakukan, dan melaksanakan evaluasi pembelajaran serta menguasai bahan atau materi pelajaran yang akan diajarkan dalam interaksi belajar mengajar. Dalam 
pelaksanaan pembelajaran guru yang profesional juga mampu memanage waktu dengan baik dan tepat sehingga mampu disiplin.

Disiplin kerja menurut Husin (2017) adalah pegawai patuh dan taat melaksanakan peraturan kerja yang berupa lisan maupun tulisan dari kelompok maupun organisasi. Ini jelas akan mempengaruhi proses belajar mengajar di kelas yang pada akhirnya adalah terganggunya proses belajar mengajar di sekolah. Akibat dari guru yang tidak masuk kerja, atau datang terlambat atau meninggalkan jam-jam pelajaran maka banyak komplain dari peserta didik tentang layanan pendidikan yang mereka terima yang berdampak pada tingkat kedisiplinan siswa baik pada jam masuk pelajaran atau tingkat pelanggaran pada tata tertib sekolah yang sering dilakukan. Hal ini mungkin dikarenakan tidak adanya tindakan atau sanksi yang tegas dan kurangnya pengawasan kepala sekolah serta jarak tempat tinggal dan tempat kerja yang jauh sehingga menyebabkan guru sering terlambat dan bermalasan dalam bekerja.

Hal tersebut mengindikasikan bahwa meningkatnya disiplin kerja yang disebabkan oleh kehadiran pegawai yang tepat waktu, tidak pernah pulang sebelum jam kerja selesai, mampu menyelesaikan pekerjaan tepat waktu, mampu menggunakan waktu secara efektif, bekerja dengan kualitas kerja baik, mengikuti prosedur dan instruksi kerja dari atasan, hadir dalam setiap rapat dan berpenampilan sopan dan berpakaian sesuai aturan yang ada maka dapat menyebabkan meningkatnya kinerja guru. Mengingat pentingnya masalah tersebut, dan untuk menyikapi kondisi tersebut diatas, maka dilakukan penelitian ini yang diharapkan dapat memberikan manfaat bagi organisasi, sehingga tujuan organisasi dapat tercapai secara optimal. Berdasarkan latar belakang diatas, maka dapat diajukan sebuah penelitian dengan judul: "Pengaruh Disiplin Kerja Terhadap Kinerja Guru Di SMK Negeri 3 Palembang".

\section{METODE}

\subsection{Jenis dan Sumber Data}

\subsubsection{Jenis Data}

Menurut Sugiyono (2016) terdapat beberapa jenis data, antara lain: 


\section{Pengaruh Disiplin Kerja Terhadap Kinerja Guru Di SMK Negeri 3 Palembang}

1. Data Kualitatif

Data kualitatif adalah data yang berbentuk kata, kalimat, skema dan gambar. Dapat juga diartikan sebagai data informasi yang berbentuk kalimat verbal bukan berupa simbol angka atau bilangan. Data kualitatif didapat melalui suatu proses menggunakan teknik analisis mendalam dan tidak bisa diperoleh secara langsung.

2. Data Kuantitatif

Data kuantitatif adalah penelitian dengan memperoleh data yang berbentuk angka. Pendekatan kuantitatif digunakan untuk mencari informasi faktual secara mendetail yang sedang menggejala dan mengidentifikasi masalahmasalah.

Dalam penelitian ini jenis data yang digunakan adalah data kualitatif yang dikuantitatifkan dengan menggunakan alat yang disebut skala likert.

\subsubsection{Sumber Data}

1. Data primer, menurut Sugiyono (2016) adalah sumber data yang langsung memberikan data kepada pengumpul data. Pengumpulan data primer dalam penelitian ini melalui cara menyebarkan kuesioner dan melakukan wawancara secara langsung dengan pihak-pihak yang berhubungan dengan penelitian yang dilakukan.

2. Data sekunder, menurut Sugiyono (2016) adalah sumber data yang diperoleh dengan cara membaca, mempelajari dan memahami melalui media lain yang bersumber dari literatur, buku-buku, serta dokumen perusahaan. Data sekunder yang di gunakan yaitu dalam bentuk dokumentasi seperti data absensi karyawan.. Adapun sumber data yang digunakan dalam penulisan penelitian adalah Data Primer.

\subsection{Populasi \& Sampel}

\subsubsection{Populasi}

Menurut Sugiyono (2016), pengertian populasi adalah wilayah generalisasi yang terdiri atas obyek/subjek yang mempunyai kualitas dan karakteristik tertentu yang ditetapkan oleh peneliti untuk dipelajari dan kemudian ditarik kesimpulannya. 
Populasi yang digunakan dalam penelitian ini adalah seluruh pegawai SMK Negri 3 Palembang yang berjumlah 56 orang.

\subsubsection{Sampel Jenuh (Sampel Sensus)}

Menurut Arikunto (2017) jika jumlah populasinya kurang dari 100 orang, maka jumlah sampelnya diambil secara keseluruhan, tetapi jika populasinya lebih besar dari 100 orang, maka bisa diambil 10-15\% atau $20-25 \%$ dari jumlah populasinya.

Berdasarkan penjelasan diatas, dikarnakan jumlah populasi tidak lebih besar dari 100 orang responden maka penulis mengambil seluruh guru yang ada pada SMK Negri 3 Palembang yaitu sebanyak 56 orang responden dengan demikian penggunaan seluruh populasi tanpa harus menarik sampel penelitian sebagai unit observasi disebut sebagai teknik sensus.

\subsection{Definisi Operasional}

Disiplin kerja merupakan variabel bebas yang dinyatakan dengan huruf $\mathrm{X}$. Menurut Rivai (2016) disiplin kerja adalah suatu alat yang digunakan para manajer untuk berkomunikasi dengan karyawan agar mereka bersedia untuk mengubah suatuperilaku serta sebagai suatu upaya untuk meningkatkan kesadaran dan kesediaanseseorang mentaati semua peraturan perusahaan dan norma-norma sosial yang berlaku.

Kinerja yang merupakan variabel terikat yang dinyatakan dengan huruf $\mathrm{Y}$. Menurut Mangkunegara (2015) kinerja merupakan hasil kerja secara kualitas dan kuantitas yang dicapai oleh seorang karyawan dalam melaksanakan tugasnya sesuai dengan tanggung jawab yang diberikan kepadanya. 


\section{Pengaruh Disiplin Kerja Terhadap Kinerja Guru Di SMK Negeri 3 Palembang}

Untuk mengetahui disiplin kerja dan pengaruhnya terhadap kinerja maka diperlukan operasionalisasi variabel. Operasionalisasi variabel dimaksudkan untuk mengetahui pengaruh melalui pengukuran variabel-variabel penelitian yang berisi variabel, dimensi, indikator dan skala.

Tabel 3.2 Operasional Variabel

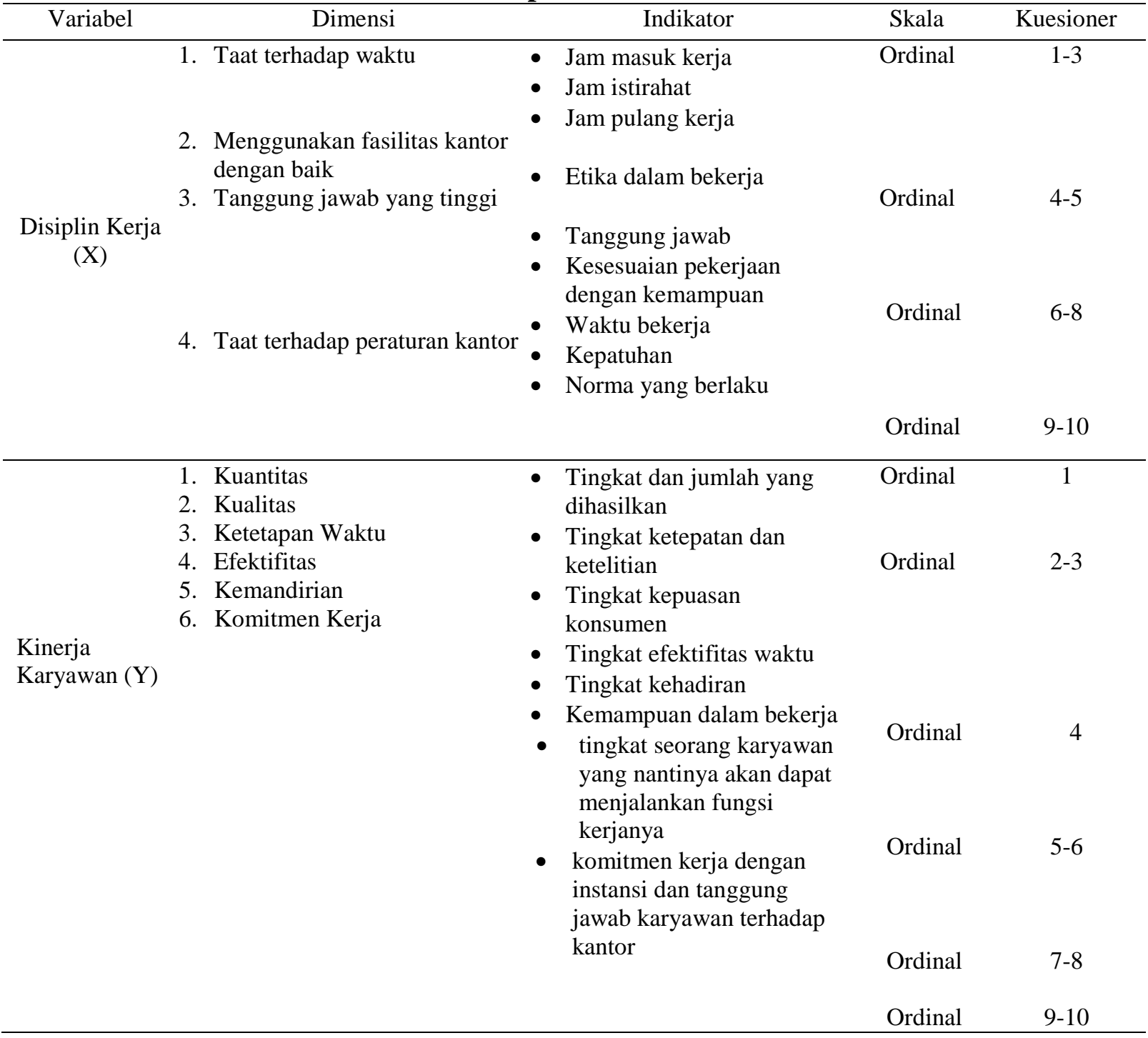

Sumber: Lateiner dalam Soejono (2016), Robbins (2018) 


\section{HASIL}

\subsection{Uji Instrumen}

\subsubsection{Uji Validitas}

Uji validitas di lakukan mengukur sejauh mana alat pengukur dapat mengukur apa yang di ukurnya. Pengujian adalah dengan nilai korelasi $(r)$ terhadap semua variabel dan butir soal. Pengujian variabel dilakukan dengan menguji correlation matrix yang ditunjukan dengan nilai $r_{\text {hitung }}>r_{\text {tabel }}$ atau sig. $r_{x y} \propto 0,05$, dimana nilai $r_{\text {tabel }}=$ $0,222(\mathrm{df}=\mathrm{n}-2,56-2=54)$ maka data dikatakan valid.

Tabel 3.1 Output Uji Validitas

\begin{tabular}{ccccc}
\hline Variable & Butir Soal & $\mathbf{r}_{\text {tabel }}$ & $\mathbf{r}_{\text {hitung }}$ & Keterangan \\
\hline & Pertanyaan 1 & 0,222 & 0,434 & Valid \\
& Pertanyaan 2 & 0,222 & 0,689 & Valid \\
& Pertanyaan 3 & 0,222 & 0,371 & Valid \\
& Pertanyaan 4 & 0,222 & 0,493 & Valid \\
X (Disiplin Kerja) & Pertanyaan 5 & 0,222 & 0,410 & Valid \\
& Pertanyaan 6 & 0,222 & 0,354 & Valid \\
& Pertanyaan 7 & 0,222 & 0,458 & Valid \\
& Pertanyaan 8 & 0,222 & 0,538 & Valid \\
& Pertanyaan 9 & 0,222 & 0,461 & Valid \\
& Pertanyaan 10 & 0,222 & 0,575 & Valid \\
& Pertanyaan 1 & 0,222 & 0,471 & Valid \\
& Pertanyaan 2 & 0,222 & 0,285 & Valid \\
& Pertanyaan 3 & 0,222 & 0,612 & Valid \\
& Pertanyaan 4 & 0,222 & 0,331 & Valid \\
& Pertanyaan 5 & 0,222 & 0,481 & Valid \\
Pegawai) & Pertanyaan 6 & 0,222 & 0,302 & Valid \\
& Pertanyaan 7 & 0,222 & 0,507 & Valid \\
& Pertanyaan 8 & 0,222 & 0,570 & Valid \\
& Pertanyaan 9 & 0,222 & Valid \\
& Pertanyaan 10 & 0,224 & Valid \\
\hline
\end{tabular}

Sumber : Output SPSS 16, diolah penulis, 2019 


\section{Pengaruh Disiplin Kerja Terhadap Kinerja Guru Di SMK Negeri 3 Palembang}

Hasil yang didapat dalam uji validitas pada variabel dependen (Kinerja Pegawai) dimana hasil data P1, P2, P3, P4, P5, P6, P7, P8, P9 dan P10 lebih besar dari $r_{\text {tabel }}(0,222)$ maka datanya semua valid. Pada variabel independen (Disiplin Kerja) dimana hasil datanya $\mathrm{P} 1, \mathrm{P} 2, \mathrm{P} 3, \mathrm{P} 4, \mathrm{P} 5, \mathrm{P} 6, \mathrm{P} 7, \mathrm{P} 8, \mathrm{P} 9$, dan $\mathrm{P} 10$ lebih besar dari $r_{\text {tabel }}(0,222)$ maka data yang dihasilkan valid.

\subsubsection{Uji Reliabilitas}

Uji reliabilitas digunakan untuk mengetahui apakah alat pengukur mempunyai keandalan dalam mengukur suatu variabel, dalam artian bahwa jika pengukuran dilakukan berulang kali akan memberikan hasil yang sama dengan setiap pengukuran. Reiability coefficient (Alpha) nilainya lebih besar dari $0,60(\alpha>0,6)$ maka variabel dan butir yang diukur dapat dipercaya atau diandalkan.

Tabel 3.2 Uji Reliabilitas

Reliability Statistics

\begin{tabular}{ccc}
\hline Variabel & \multicolumn{2}{c}{ Keterangan } \\
\hline Disiplin Kerja & Cronbach's Alpha & N of Items \\
Kinerja Pegawai &, 857 & 20 Reliabel \\
&, 855 & 20 Reliabel \\
\hline
\end{tabular}

Sumber: Output SPSS 16, diolah penulis 2019

Hasil uji dari reliabilitas pada kedua variabel yaitu variabel Disiplin Kerja (X) dan varibel Kinerja Pegawai $(\mathrm{Y})$ seluruhnya menunjukkan nilai Cronbach's Alpha berada diatas 0,60 (Cronbach's Alpha $>0,60$ ). Hasil ini berarti instrumen variabel yang digunakan memenuhi syarat sebagai alat ukur dan dapat diandalkan.

\subsection{Uji Signifikansi Parsial (Uji t)}

Uji $\mathrm{t}$ digunakan untuk mengetahui seberapa besar pengaruh variabel independen secara parsial (individu) dalam menerangkan variasi variabel dependen. 
Berdasarkan tingkat signifikan masing-masing variabel independen, jika memiliki tingkat signifikan $<\alpha 0,05$, maka variabel tersebut mempunyai pengaruh terhadap variabel dependen. Dari hasil pengolahan data dengan SPSS pada tabel 4.5 dapat diketahui hasil Uji-t (Uji Parsial).

Tabel 3.3 Output Uji-t

Coefficients $^{\mathbf{a}}$

\begin{tabular}{|c|c|c|c|c|c|c|c|}
\hline \multirow{2}{*}{\multicolumn{2}{|c|}{ Model }} & \multicolumn{2}{|c|}{$\begin{array}{c}\text { Unstandardized } \\
\text { Coefficients }\end{array}$} & \multirow{2}{*}{$\begin{array}{c}\begin{array}{c}\text { Standardized } \\
\text { Coefficients }\end{array} \\
\text { Beta }\end{array}$} & \multirow[b]{2}{*}{$\mathrm{t}$} & & \multirow[b]{2}{*}{ Sig. } \\
\hline & & B & Std. Error & & & & \\
\hline \multirow[t]{2}{*}{1} & (Constant) & 15.000 & 3.875 & & & 3.871 & .000 \\
\hline & Disiplin Kerja & .584 & .110 & .586 & & 5.309 & .000 \\
\hline
\end{tabular}

a. Dependent Variable: Kinerja Pegawai

Sumber : Output SPSS 16, diolah penulis, 2019

Diketahui jumlah sampel $(n)=56$ dan jumlah variabel independen dan variabel dependen $(k)=2$, maka diperoleh $d f=54(d f=n-k)$ yang menunjukkan nilai $t_{\text {tabel }}$ sebesar 1,674 dengan probabilitas dua arah (two-tailed) 0,05. Berdasarkan tabel 4.6 di atas, maka dapat diketahui pengaruh disiplin kerja terhadap Kinerja Pegawai yaitu Berdasarkan tabel nilai $t_{\text {hitung }}$ untuk variabel Disiplin Kerja adalah sebesar 5,309 dan $t_{\text {tabel }}$ dengan $\alpha=5 \%$ dengan demikian $t_{\text {hitung }}$ lebih besar dari $t_{\text {tabel }}(5,309>1,674)$, artinya Disiplin Kerja berpengaruh secara Positif. Tingkat pengaruh signifikan Disiplin Kerja terhadapKinerja Pegawai kurang dari 5\% $(\alpha=0,000)$ artinya Disiplin Kerja berpengaruh dan signifikan terhadapKinerja Pegawai guru.

\section{PEMBAHASAN}

Hasil penelitian ini menunjukkan bahwa Disiplin Kerja secara parsial berpengaruh signifikan terhadap Kinerja Pegawai. Kondisi ini berarti kemampuan Sekolah telah maksimal dalam menjalankan kegiatan operasionalnya sehingga kedisiplinan yang dihasilkan sekolah baik. 


\title{
Pengaruh Disiplin Kerja Terhadap Kinerja Guru Di SMK Negeri 3 Palembang
}

\begin{abstract}
Disiplin kerja adalah suatu alat yang digunakan para manajer untuk berkomunikasi dengan karyawan agar mereka bersedia untuk mengubah suatu perilaku serta sebagai suatu upaya untuk meningkatkan kesadaran dan kesediaanseseorang mentaati semua peraturan perusahaan dan norma-norma sosial yang berlaku Rivai (2016). Menurut Mangkunegara(2015) mengemukakan bahwa kinerja merupakan hasil kerja secara kualitas dan kuantitas yang dicapai oleh seorang karyawan dalam melaksanakan tugasnya sesuai dengan tanggung jawab yang diberikan kepadanya.

Hasil penelitian dari Dwi Agung Nugroho Arianto (2015) secara uji yang dilakukan disiplin kerja, lingkungan dan budaya kerja berpengaruh signifikan terhadap kinerja pegawai.

Disiplin Kerja masih bisa diberikan kepada para pegawai dengan mengikuti peraturan. Hal ini menyebabkan Kinerja pegawai mengalami kenaikan karena kedisiplinan kerja yang diberikan ke pegawai.
\end{abstract}

\section{SIMPULAN}

Guru yang profesional adalah guru yang menerapkan prinsip kedisiplinan. Penelitian merupakan penelitian kuantitaif yang bertujuan untuk mengetahui seberapa besar pengaruh Disiplin Kerja (X1) terhadap variabel dependent Kinerja Guru di SMK Negeri 3 Palembang. Teknik yang digunakan dalam pengambilan sampel adalah purposive sampling. Jumlah sampel yang digunakan dalam penelitian sebanyak 56 responden. Instrumen pengukuran variabel adalah validitas dan reliabilitas sedangkan teknik analisis yang digunakan uji $\mathrm{T}$ dan analisis regresi sederhana. Dari hasil uji T (parsial), Disiplin Kerja (X1) berpengaruh terhadap Kinerja Gurudi SMK Negeri 3 Palembang. Sehingga Hasil penelitian ini menunjukkan bahwa 
Disiplin Kerja berpengaruh signifikan terhadap Kinerja Pegawai Guru SMK Negeri 3 Palembang.

\section{UCAPAN TERIMAKASIH}

Ucapan terima kasih saya persembahkan Kepala Sekolah SMP N 03 Palembang yang telah memberikan dukungan dalam penyusunan artikel ini. Kedua orang tua dan keluarga serta teman-teman Magister Manajemen yang selalu memberikan dukungan. Kemudian, khsususnya bagi pengelola jurnal UTILITY yang telah bersedia menerbitkan tulisan ini. Terimakasih.

\section{REFERENSI}

Arianto, Dwi Agung Nugroho. 2015. Pengaruh disiplin kerja, lingkungan kerja dan budaya kerja terhadap kinerja tenaga pengajar. Jurnal economia Vol. 9 No.2

Arikunto, S. 2017.Prosedur Penelitian Suatu Pendekatan Praktik. Edisi Revisi. Jakarta: PT. Rineka Cipta

Husin, Umar. 2017. Riset Sumber Daya Manusia Dalam Organisasi. Edisi Revisi. Jakarta: PT. Gramedia Pustaka Utama.

Mangkunegara, A. P. 2015. Manajemen Sumberdaya Manusia Perusahaan. Bandung:PT. Remaja Rosdakarya.

Mathis, Robert L. dan Jackson, John H. 2006. Human Resoursce Management, Alih Bahasa. Jakarta : Salemba Empat.

Robbins, Stephen P. (2018). Perilaku Organisasi. Edisi kesepuluh. Jakarta: PT Indeks Kelompok Gramedia

Singodimedjo dalam Edi Sutrisno, 2011. Manajemen Sumber Daya Manusia. Dsiplin Kerja Jakarta : Kencana

Sugiyono. 2016. Metode Penelitian Kuantitatif dan R\&D. Bandung: Alfabeta

Veithal, Rivai. 2016. Manajemen Sumber Daya Manusia Untuk Perusahaan, Cetakan Pertama. Jakarta : PT Raja Grafindo Persada

Wahyuni, Trisacti. 2015. Anggaran Berbasis Kinerja, Jurnal Anggaran. Jakarta 